\title{
Oxidative and non-oxidative glucose metabolism in non-obese Type 2 (non-insulin-dependent) diabetic patients
}

\author{
A. Golay ${ }^{1}$, R.A.DeFronzo ${ }^{5}$, E. Ferrannini ${ }^{6}$, D.C.Simonson ${ }^{4}$, D. Thorin ${ }^{1}$, K. Acheson ${ }^{2}$, D. Thiébaud ${ }^{1}$, B.Curchod ${ }^{3}$, \\ E. Jéquier ${ }^{2}$ and J.P.Felber ${ }^{1}$ \\ ${ }^{1}$ Division of Endocrinology and Clinical Biochemistry, CHUV, ${ }^{2}$ Institute of Physiology, Lausanne University, ${ }^{3} \mathrm{Clinic}$ La Source, Lausanne, \\ Switzerland, ${ }^{4}$ Department of Medicine, Yale University School of Medicine, New Haven, Connecticut, ${ }^{5}$ Diabetes Division, Department of \\ Medicine, University of Texas Health Science Center, San Antonio, Texas, USA, ${ }^{6}$ University of Pisa, Italy
}

\begin{abstract}
Summary. Insulin resistance is a common feature of Type 2 (non-insulin-dependent) diabetes mellitus. This defect in insulin-mediated glucose metabolism could result from a defect in either glucose oxidation or non-oxidative glucose disposal. To examine this question, euglycaemic insulin clamp studies were performed in 16 normal weight Type 2 and 11 age-matched control subjects. In Type 2 diabetic patients the fasting plasma glucose concentration, $8.39 \pm 0.50 \mathrm{mmol} / 1$, was allowed to decline (over $54 \pm 6 \mathrm{~min}$ ) to $5.33 \pm 0.11$ mmol/ 1 before starting the insulin clamp. Total body glucose uptake was significantly decreased in Type 2 diabetic patients vs control subjects $\left(148 \pm 15\right.$ vs $264 \pm 25 \mathrm{mg} / \mathrm{min} \cdot \mathrm{m}^{2}$, $p<0.001)$. Both total glucose oxidation (59 \pm 6 vs $\left.89 \pm 6 \mathrm{mg} / \mathrm{min} \cdot \mathrm{m}^{2}, p<0.005\right)$ and non-oxidative glucose disposal $\left(89 \pm 15\right.$ vs $\left.179 \pm 24 \mathrm{mg} / \mathrm{min} \cdot \mathrm{m}^{2}, p<0.005\right)$ were signi-
\end{abstract}

ficantly reduced in the Type 2 diabetic patients. Basal glucose oxidation was also reduced in the Type 2 diabetic patients $\left(22 \pm 3\right.$ vs $\left.38 \pm 5 \mathrm{mg} / \mathrm{min} \cdot \mathrm{m}^{2}, p<0.01\right)$. In conclusion, during the postabsorptive state and under conditions of euglycaemic hyperinsulinaemia, impairment of glucose oxidation and non-oxidative glucose disposal both contribute to the insulin resistance observed in normal weight Type 2 diabetic patients. Since lipid oxidation was normal in this group of diabetic patients, excessive non-esterified fatty acid oxidation cannot explain the defects in glucose disposal.

Key words: Insulin-mediated glucose uptake, glucose oxidation, non-oxidative glucose disposal, lipid oxidation, insulin resistance.
Patients with Type 2 (non-insulin-dependent) diabetes mellitus form a heterogeneous group in whom both insulin deficiency and insulin resistance contribute to the impairment in glucose utilisation [1]. With respect to the insulin resistance, defects in peripheral glucose uptake [2-11] and suppression of hepatic glucose metabolism $[3,4,9,12]$ have been described. The defect in insulin-mediated glucose metabolism has been documented with a variety of techniques, including the insulin clamp [2-5], forearm perfusion [6-8, 10], insulin tolerance test $[13,14]$ and insulin suppression test $[5,9]$. All of these techniques primarily examine peripheral, muscle, glucose uptake $[15,16]$. In the most general sense, the glucose which is taken up by peripheral tissues can have one of three major metabolic fates: (1) oxidation to carbon dioxide and water [15]; (2) storage, primarily in the form of glycogen [17]; or (3) conversion to lactate [15].

In obese Type 2 diabetic patients, defects in both oxidative and non-oxidative pathways of glucose utilisation have been described [18-21]. Further, it has been suggested that the impairment in glucose utilisation results from an increased rate of lipid oxidation $[18,19,21]$. Thus, according to the glucose/fatty acid cycle first proposed by Randle [22, 23], increased lipid oxidation impairs glucose oxidation by altering the redox potential of the cell and inhibiting several key enzymes in the glycolytic cascade. Experimental validation of this glucose/fatty acid cycle has been provided both in man [24, 25] and animals [26, 27].

In contrast to the obese diabetic patient, no previous study has examined whether the insulin resistance in normal weight Type 2 diabetic patients results from an impairment in oxidative versus non-oxidative glucose utilisation and whether such defects, if present, are related to an accelerated rate of lipid oxidation. In the absence of obesity one might not expect plasma non-esterified fatty acid levels and lipid oxidation to be increased.

In the present study we have employed the insulin clamp technique [28] in combination with indirect calorimetry to: (1) assess the relative contributions of 
defects in glucose oxidation versus non-oxidative glucose disposal to the overall impairment in total body glucose utilisation in normal weight Type 2 diabetic patients, and (2) examine whether any of the observed defects in glucose disposal are related to an enhanced rate of lipid oxidation.

\section{Subjects and methods}

\section{Subjects}

Sixteen non-obese Type 2 diabetic patients ( 14 males $/ 2$ females; age $=54 \pm 2$ years) were compared to 11 age-matched non-obese, non-diabetic subjects ( 10 males $/ 1$ female; age $=53 \pm 2$ years). All subjects were within $25 \%$ of ideal body weight based on medium frame individuals from the Metropolitan Life Insurance Tables, 1959. The body mass index ( $25 \pm 1 \mathrm{vs} 23 \pm 1 \mathrm{~kg} / \mathrm{m}^{2}$ respectively) was similar in the diabetic and control groups. There was no family history of obesity or diabetes mellitus in any of the control individuals and none was taking any medication. The fasting plasma glucose concentration in the diabetic patients on the day of study was 8.39 $\pm 0.50 \mathrm{mmol} / 1$. Fasting glucose levels, determined on at least three occasions during the three months prior to study, agreed closely with this value. All of the diabetic patients were being treated with diet alone. None had ever received insulin or an oral hypoglycaemic agent. The mean duration of diabetes was $4 \pm 1$ years. None of the diabetic patients had any evidence of diabetic retinopathy or diabetic neuropathy on routine physical examination. No subject had evidence of diabetic nephropathy as evidenced by a negative urine test for albumin. There was no evidence of any other major organ system disease or endocrine abnormality other than diabetes on a routine history and physical examination. A physical activity history was obtained on all control subjects and diabetic patients; none were participating in any unusual exercise programs and none were excessively sedentary.

All subjects were consuming a weight-maintaining diet containing at least $250-300 \mathrm{~g}$ of carbohydrate per day for 3 days before each study. The distribution of calories, obtained by dietary history, was about $50 \%$ carbohydrate, $20 \%$ protein and 30\% fat. Prior to their participation the nature, purpose and risks of the study were carefully explained to all subjects and their voluntary consent was obtained. The experimental protocol was submitted to and approved by the human investigation committee of the Department of Medicine of the University of Lausanne, Switzerland and by the Yale University School of Medicine, New Haven, Connecticut, USA. All studies were performed in Lausanne.

\section{Experimental protocol}

Studies were performed in the recumbent position at 08.00 hours following a $10-12 \mathrm{~h}$ overnight fast. A teflon catheter was inserted into an antecubital vein for the infusion of all test substances. For blood sampling, a second catheter was inserted retrogradely into a wrist vein and kept patent with an infusion of isotonic saline. The hand was inserted into a heated box $\left(70^{\circ} \mathrm{C}\right)$ to achieve arterialisation of the venous blood [29]. Sixty min prior to beginning the insulin clamp studies, continuous respiratory exchange measurements were begun and continued throughout the duration of the experimental protocol.

\section{Euglycaemic insulin clamp}

After a 60-min equilibration period, a prime-continuous infusion of crystalline porcine insulin was administered. In control subjects the plasma glucose concentration was maintained constant at basal le- vels by determination of the plasma glucose concentration every 5 min and periodically adjusting a variable $20 \%$ glucose solution based on a negative feedback principle [28]. Under these steady state conditions of constant glycaemia, the rate of glucose infusion provides an index of total body glucose uptake since hepatic glucose production is suppressed by over $90-95 \%$ in control subjects and in diabetic patients with a comparable degree of fasting hyperglycaemia $[2,3,30,31]$. The continuous insulin infusion was given at $40 \mathrm{mU} / \mathrm{m}^{2} \cdot \min$ in all subjects. This infusion rate was chosen because it produces portal insulin levels slightly less than observed during a standard oral glucose tolerance test (OGTT) [32] while peripheral insulin levels are slightly greater than observed during an OGTT [33,34] or mixed meal [35]. In the control group the duration of each insulin clamp study was $120 \mathrm{~min}$. In the Type 2 diabetic pa. tients the glucose infusion rate was not begun until the plasma glucose had declined to approximately $5.5 \mathrm{mmol} / \mathrm{l}$, at which level it was held constant. The mean time for the plasma glucose concentration to decline to euglycaemic levels was $54 \pm 6 \mathrm{~min}$. The duration of the insulin clamp from the time that euglycaemia was achieved was $120 \mathrm{~min}$.

\section{Respiratory exchange measurements}

During the 60 -min control period and throughout the 2-h insulin clamp study, substrate utilisation rates were determined by computerised open-circuit indirect calorimetry using a ventilated hood as previously described [17]. Briefly, a transparent plastic ventilated hood is placed over the subject's head and made airtight around the neck. To avoid air loss, a slight negative pressure is maintained in the hood. Ventilation was measured with a massic flowmeter (Setaram, Lyon, France). A constant fraction of the air flowing out of the hood was automatically collected for analysis. The oxygen content was continuously measured by a thermomagnetic analyser (Hartmann and Braun, Frankfurt, FRG) and carbon dioxide content by an infrared analyser (Hartmann and Braun). The non-protein respiratory quotient was calculated from calorimetric values and urinary nitrogen. Determination of carbohydrate oxidation rate was obtained as previously described [17]. The quantity of urinary nitrogen excreted during the entire period of calorimetry (i.e. basal plus insulinstimulated state) was used to obtain an index of the amount of protein oxidised; this calculation assumes that protein oxidation was relatively constant throughout the entire study period. It should be noted, however, that this assumption does not substantially affect the calculation of carbohydrate or lipid oxidation [35].

\section{Analytical procedures}

Plasma glucose concentration was determined in duplicate by the glucose oxidase method on a Beckman Glucose Analyzer II (Beckman Instrument Inc., Fullerton, Calif, USA). Plasma immunoreactive insulin was determined by radioimmunoassay as described by Herbert et al. [36]. Plasma non-estrified fatty acids were extracted using the method of Dole and Meinertz [37] and determined according to the method of Heindel et al. [38]. Glucagon was determined by radioimmunoassay as described by Aguilar-Parada et al. [39]. Urinary nitrogen was measured by the method of Kjeldahl [40]. Plasma catecholamines were measured with a radioenzymatic method (Cata-Kit, Upjohn, Kalamazoo, Mich, USA).

\section{Data analysis}

During the 120-min insulin clamp study the glucose infusion rate was calculated at 20-min intervals and the mean value from $60-120 \mathrm{~min}$ is presented. All results are expressed in $\mathrm{mg} / \mathrm{m}^{2} \cdot \mathrm{min}$. The rationale for expressing the data per $\mathrm{m}^{2}$ surface area is that lean 
body mass (measured directly by the antipyrine technique) can be predicted from body weight and height with multiple correlation coefficients of 0.96 and 0.83 , respectively, in males and females of normal body weight or moderate obesity [41]. The rate of total body glucose disposal presented in the text represents the mean glucose infusion rate during the $60-120 \mathrm{~min}$ time period of the euglycaemic insulin clamp. 'This calculation assumes that hepatic glucose production is completely suppressed in both control subjects and diabetic patients, and we have previously documented the validity of this assumption in a large group of normal weight Type 2 diabetic individuals $[2,3,31]$

The glucose oxidation rate was calculated from calorimetric measurements for 5-min intervals during the basal state and throughout the 120-min insulin clamp period. In the diabetic group basal glucose oxidation was calculated during the 45 min preceding the initiation of insulin infusion. Non-oxidative glucose utilisation was calculated by subtracting the rate of glucose oxidation during a given time period from the total rate of glucose uptake during the same time period. Presented values for glucose oxidation and nonoxidative glucose disposal represent the mean for the 60-120 min time interval and are expressed in $\mathrm{mg} / \mathrm{m}^{2} \cdot \mathrm{min}$. To calculate the steady state plasma insulin and glucose concentrations the mean of values (every $5 \mathrm{~min}$ for glucose and every $10 \mathrm{~min}$ for insulin) from $60-120 \mathrm{~min}$ was employed. The mean values during the $60-120 \mathrm{~min}$ time period were chosen to allow insulin to more fully exert its biological effects.

\section{Statistical analysis}

All values in the text represent the mean \pm SEM. Comparisons between the Type 2 diabetic and control groups were performed with the unpaired Student's t-test.

\section{Results}

Plasma glucose, non-estrified fatty acid, insulin, and glucagon concentrations (Fig. 1)

The mean fasting plasma glucose concentration in the Type 2 group was $8.39 \pm 0.50 \mathrm{mmol} / 1$ versus $5.17 \pm$ $0.17 \mathrm{mmol} / 1$ in the control group ( $p<0.001$, Fig. 1 ). During the last $60 \mathrm{~min}$ of euglycaemic insulin clamp, the steady-state plasma glucose values were similar in diabetic patients, $5.33 \pm 0.11 \mathrm{mmol} / 1$, and control subjects, $5.17 \pm 0.17 \mathrm{mmol} / \mathrm{l}$. The stability of the plasma glucose concentration is reflected by the coefficients of variation which ranged between 2.5 and $5.5 \%$.

The fasting plasma insulin concentration was significantly elevated in the non-obsese diabetic group compared to the control group, $16 \pm 2$ vs $11 \pm 1 \mathrm{mU} / 1$ $(p<0.05)$. The steady-state plasma insulin levels during the $60-120 \mathrm{~min}$ time period were $97 \pm 6$ and $90 \pm$ $6 \mathrm{mU} / 1$, respectively, with coefficients of variation ranging from 6 to $14 \%$.

The fasting plasma glucagon concentration was similar in the control, $91 \pm 7 \mathrm{pg} / \mathrm{ml}$, and diabetic, $98 \pm 9 \mathrm{pg} / \mathrm{ml}$, groups. During the insulin clamp the decline in plasma glucagon was similar in both groups, $77 \pm 5$ versus $67 \pm 9 \mathrm{pg} / \mathrm{ml}$ respectively. The fasting epinephrine and norepinephrine levels were $43 \pm 4$ and $223 \pm 13 \mathrm{pg} / \mathrm{ml}$, respectively, in the diabetic groups.
During the insulin clamp study neither the epinephrine $(52 \pm 6)$ nor norepinephrine $(230 \pm 14)$ concentrations changed significantly from baseline in the diabetic patients.

In the postabsorptive state the plasma non-esterified fatty acid (NEFA) concentration was similar in diabetic, $628 \pm 45 \mu \mathrm{mol} / 1$, and control, $575 \pm 98 \mu \mathrm{mol} / 1$, groups. Following hyperinsulinaemia the absolute plasma NEFA level was slightly greater in the Type 2 diabetic vs control group, $207 \pm 21$ vs $142 \pm 8 \mu \mathrm{mol} / 1(p<0.05)$; the decrement in plasma NEFA was similar in diabetic and control groups, $420 \pm 47$ vs $434 \pm 92 \mu \mathrm{mol} / \mathrm{l}$. Within the weight range examined there was no correlation between body mass index and the fasting plasma NEFA level or the basal rate of lipid oxidation in either diabetic or control groups.

\section{Glucose metabolism (Table 1)}

In the basal state the rate of glucose oxidation was reduced by approximately $40 \%(p<0.01)$ in the Type 2 diabetic patients as compared to the control subjects. During the 60-120 min time period of the insulin clamp study, glucose oxidation rose about 2.5 -fold in both diabetic and control groups $(p<0.01$, Table 1$)$. In the diabetic patients, however, the absolute total rate of glucose oxidation after insulin administration was still $34 \%$ lower than in the control subjects $(p<0.01)$, and the increment in glucose oxidation above basal values (suprabasal glucose oxidation) was reduced by $31 \%(p<0.02)$. Likewise, the post-insulin rate of nonoxidative glucose disposal in diabetic patients was $50 \%$ lower than in control subjects $(p<0.005$, Table 1$)$. As a consequence, the total rate of glucose uptake during the clamp was reduced by $43 \%$ in Type 2 diabetic patients compared to control subjects $(p<0.001)$. The time course of change in total glucose uptake, glucose oxidation, and non-oxidative glucose disposal is displayed in Figure 2.

The estimated rate of glucose disposal in the Type 2 diabetic group during the initial falling glucose phase after starting insulin was $141 \pm 14 \mathrm{mg} / \mathrm{m}^{2} \cdot \mathrm{min}$. This was calculated by multiplying the rate of plasma glucose decline by the space of glucose distribution (assumed to be 25\%). This estimated rate of glucose utilisation correlated well with the value, $148 \pm$ $15 \mathrm{mg} / \mathrm{m}^{2} \cdot \mathrm{min}$, observed during the insulin clamp $(r=0.900, p<0.001)$.

\section{Protein and lipid metabolism}

The rate of protein oxidation was $39 \%$ greater in the Type 2 diabetic compared to the control group, $p<0.05$ (Table 1). In the postabsorptive and insulinstimulated states, the rate of lipid oxidation was similar in diabetic and control groups (Table 1). The basal 

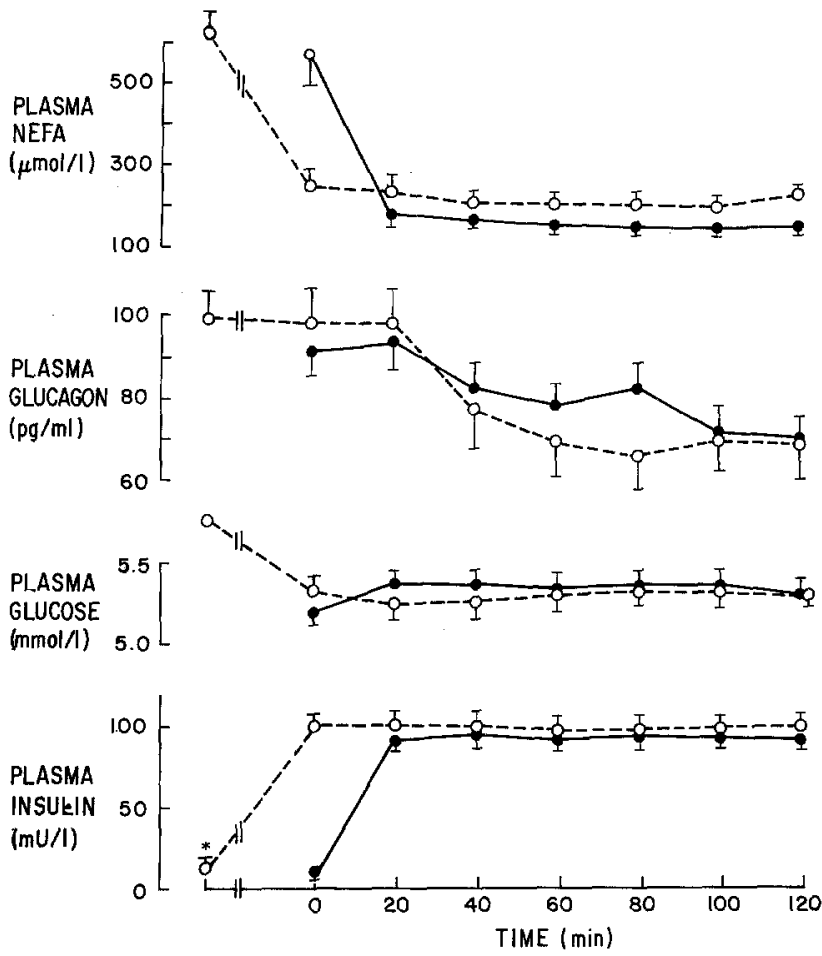

Fig.1. Time related change in plasma glucose, non-esterified fatty acids (NEFA), insulin, and glucagon concentrations in control subjects $(\bullet)$ and normal weight Type 2 diabetic patients (O) during the insulin clamp. All values represent the mean \pm SEM. In Type 2 patients the first point on the curve $(t=$ zero) represents the basal value before insulin infusion

rate of lipid oxidation was inversely correlated with the basal rate of glucose oxidation in the Type 2 diabetic patients $(r=-0.667, p<0.001)$, in the control subjects $(r=-0.699, p<0.01)$ and in both groups combined $(r=-0.678, p<0.001)$. During the insulin clamp the rates of lipid and glucose oxidation also were inversely correlated in the Type 2 diabetic patients $(r=-0.624, p<0.001)$, control subjects $(r=-0.604$, $p<0.01)$, and both groups combined $(r=-0.638, p<$ 0.001 ). No correlation was observed between the basal rate of lipid oxidation and total glucose uptake or nonoxidative glucose disposal during the insulin clamp. Similarly, there was no correlation between the rate of lipid oxidation during the insulin clamp and either the total rate of glucose uptake or non-oxidative glucose disposal during the insulin clamp.

\section{Discussion}

Under conditions of hyperinsulinaemia, hepatic glucose production is inhibited and glucose uptake by peripheral tissues is stimulated in a dose-dependent fashion [15, 42]. As we have previously shown, the major metabolic fate of the glucose that is taken up by cells involves: (1) oxidation to carbon dioxide and water [15]; (2) storage [15], presumably as glycogen [43]; and (3) conversion to lactate [15]: Although it is well established that the total amount of glucose taken up by the entire body in normal weight Type 2 diabetic patients is diminished following insulin infusion [1-5], no previous studies have examined whether this defect involves impaired glucose oxidation or impaired non-oxidative glucose uptake or both. The present results indicate that both processes are defective in Type 2 diabetes mellitus. When the plasma insulin concentration was raised by approximately $100 \mathrm{mU} / 1$, the total amount of glucose metabolised by the diabetic patient was reduced by $44 \%$ compared to age- and weight-matched control subjects. This reduction is quantitatively similar to results previously reported [2-5] in Type 2 diabetic patients with similar degrees of fasting hyperglycaemia and was accounted for both by a decrease in insulin-mediated glucose oxidation and in non-oxidative glucose disposal.

In the postabsorptive state the rate of glucose oxidation also was significantly reduced in normal weight Type 2 diabetic patients by $42 \%(p<0.01$, Table 1$)$. It is likely, however, that the true rate of glucose oxidation in the basal state is somewhat underestimated by the technique of indirect calorimetry since oxidation of glucose derived from amino acids through gluconeogenesis is not accounted for as glucose but as protein oxidation [44]. This is so since protein oxidation is subtracted from the total respiratory quotient for the calculation of the non-protein respiratory quotient. In the postabsorptive state it is unlikely that fuels, other than amino acids, could have contributed to an underestimation of glucose oxidation to any significant extent.

Recently, several papers have appeared in which glucose oxidation/storage have been examined in obese Type 2 diabetic patients [18-21]. Boden et al. [20] demonstrated normal rates of glucose oxidation in the postabsorptive state whereas Bogardus, Ravussin and

Table 1. Glucose, lipid and protein metabolism in normal weight Type 2 diabetic patients and control subjects (mean \pm SEM)

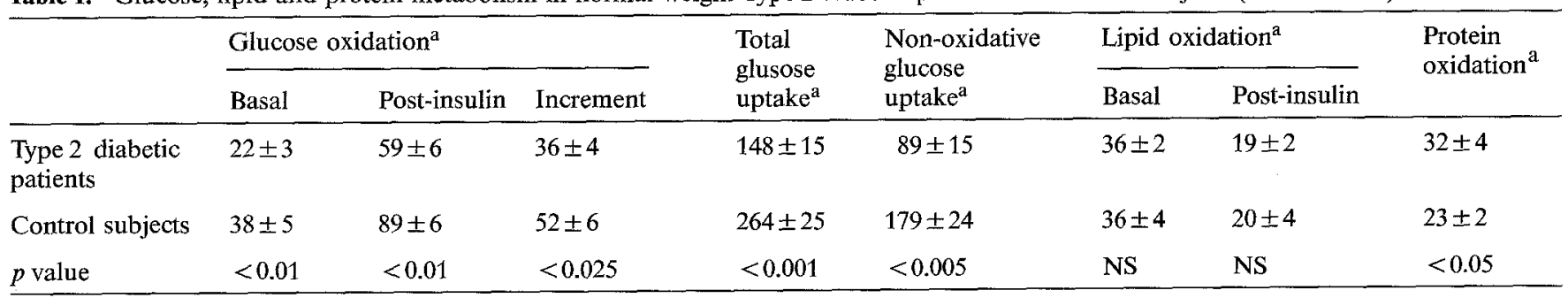

all data are expressed in $\mathrm{mg} / \mathrm{m}^{2} \cdot \mathrm{min} ; \mathrm{NS}=$ not significant 

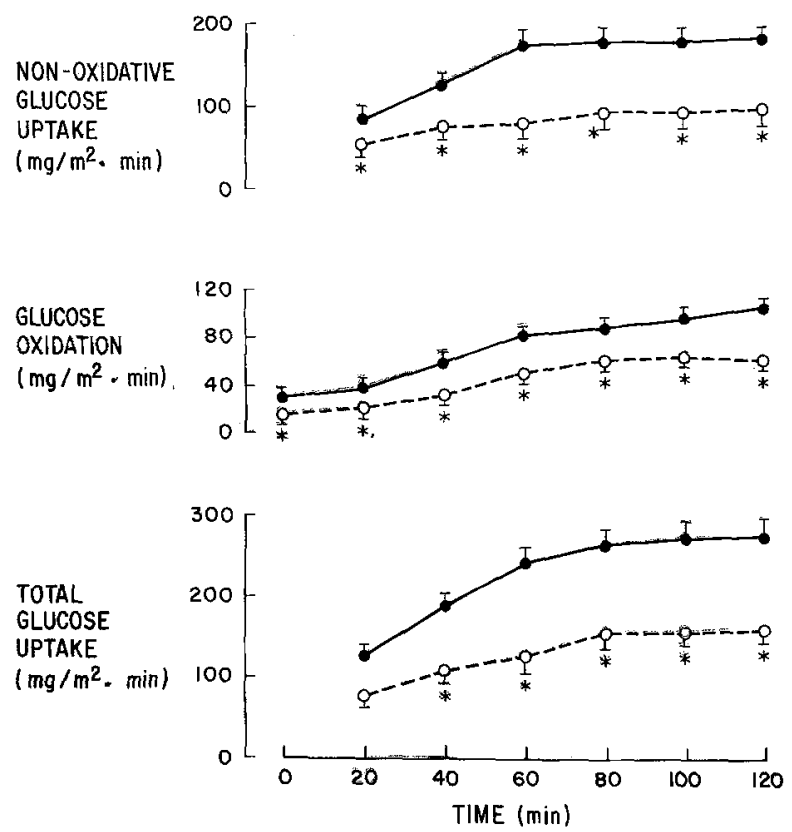

Fig. 2. Time related change in total body glucose uptake (assuimed to be equal to the infusion rate of exogenous glucose) in control subjects $(\bullet)$ and in normal weight Type 2 diabetic patients $(\theta)$ during the insulin clamp. All values represent the mean $\pm \mathrm{SEM} .{ }^{*} p<0.01$

coworkers $[19,21]$, in obese diabetic Pima Indians, found a significant decrease in basal glucose oxidation. The reason(s) for the difference in basal glucose oxidation rates between Boden et al. [20] and Bogardus et al. [19, 21], as well as ourselves, is not clear at present but may be explained by differences in the patient populations (i.e. our patients were normal weight; the patients in Boden were obese Caucasions; those of Bogardus were obese Pima Indians) or serverity of diabetes. The results from all three groups [19-21, and ours] are consistent in that following hyperinsulinaemia the increase in glucose oxidation and non-oxidative glucose uptake both were significantly impaired.

In the postabsorptive state we found that the rate of lipid oxidation was strongly and inversely correlated to the rate of glucose oxidation in both diabetic and control groups $(-0.678, p<0.001)$. Similarly, following hyperinsulinaemia the rates of insulin-mediated glucose and lipid oxidation were inversely correlated in both diabetic and control groups $(r=-0.638$, $p<0.001$ ). These results suggest that the rate of lipid oxidation is an important determinant of glucose oxidation in both control subjects and diabetic patients and that the normal insulin-mediated decline in lipid oxidation is, in part, responsible for the rise in glucose oxidation. Thus, our data provide evidence that the Randle cycle [22, 23] is operative in regulating glucose oxidation both in the postabsorptive state and following insulin administration. These resuilts are consistent with observations that lipid infusion inhibits the ability of insulin to enhance glucose oxidation $[24,25,45,46]$. It is important to point out, how- ever, that neither the basal rate of lipid oxidation, nor the rate of lipid oxidation during the insulin clamp, were elevated in Type 2 diabetic patients compared to control subjects (Table 1). Since neither the basal rate of lipid oxidation nor the rate of lipid oxidation during the insulin clamp was elevated in our normal weight Type 2 patients, it is obvious that increased Randle cycle activity cannot explain the defects in glucose oxidation or non-oxidative glucose uptake observed during the postabsorptive and insulin-stimulated states. In contrast, in obese Type 2 diabetic patients lipid oxidation under basal conditions, as well as in the insulin-stimulated state, is increased and correlates inversely with the defect in glucose oxidation $[18,19,21]$. Similarly, Lillioja et al. [47] have reported an inverse relationship between basal and insulin-stimulated carbohydrate and lipid oxidation in obese, non-diabetic Pima Indiañs:

From a quantitative standpoint impaired glucose oxidation and non-oxidative glucose disposal contribute about $30 \%$ and $70 \%$, respectively, to the defect in total body insulin-stimulated glucose metabolism in Type 2 diabetic patients (Täble 1). In a previous study Meyer et al. [17] reported a similar decrease in glucose storage in the course of a $100 \mathrm{~g}$ OGTT. This was explained by a decrease in the plasma insulin response to the glucose load. In the present study, with comparable glucose and steady state plasma insulin levels of approximately $100 \mathrm{mU} / 1$ in diabetic and control groups, the lower rate of non-oxidative glucose uptake in Type 2 diabetic patients suggests that the ability of insulin to stimulate non-oxidative pathways of glucose metabolism is impaired in Type 2 diabetes mellitus.

It is well known that hyperglycaemia per se, by a mass action effect, enhances tissue glucose uptake and augments the rate of insulin-mediated glucose metabolism $[42,43,48]$. In addition, we have shown that the mass action effect of hyperglycaemia to stimulate glucose uptake is impaired in Type 2 diabetic patients [49]. Therefore, the present studies were performed after lowering the plasma glucose concentration to euglycaemic levels. In the diabetic group, it took $54 \pm 6 \mathrm{~min}$ for the plasma glucose concentration to decline from 8.39 to $5.33 \mathrm{mmol} / 1$. Thus, insulin had approximately one hour longer to exert its effect on glucose metabolism in the diabetic versus control group. Since the ability of insulin to stimulate glucose uptake and oxidation increases as a function of time during the second to third hour of an insulin clamp [50,51], if anything, one would have expected a higher rate of glucose oxidation and uptake in the Type 2 diabetic group. Thus, it is likely that our experimental design could have underestimated the magnitude of the deiect in glucose oxidation and total body glucose uptake in the diabetic patients. One additional factor that needs to be considered in interpreting the reduced rates of insulin-mediated glucose oxidation in the Type 2 diabetic patients is the possible release of 
counterregulatory hormones as the plasma glucose concentration declined from hyperglycaemic to euglycaemic levels [52]. With regard to this concern neither plasma glucagon, epinephrine, or norepinephrine lev. els rose significantly during the 174 -min insulin clamp study in the diabetic group. One additional observation suggests that release of counterregulatory hormones did not exert any effect on glucose metabolism during the insulin clamp. The rate of glucose uptake, estimated from the fall in plasma glucose concentration during the period after starting the insulin infusion, when no exogenous glucose was being infused, was strongly correlated with the rate of glucose uptake measured during the insulin clamp study. If a significant release of counterregulatory hormones had occurred and these hormones exhibited an insulin-antagonistic effect on glucose metabolism, such a strong correlation would not have been expected.

In summary, the present results indicate that insulin-mediated glucose metabolism is impaired in normal weight Type 2 diabetic patients and that this impairment results from a diminution in both glucose oxidation and non-oxidative glucose disposal. Basal lipid oxidation is not elevated in normal weight Type 2 diabetic individuals and suppresses normally in response to insulin.

Acknowledgements. This work was supported in part by the Swiss National Science Foundation (Grant No.3770080), by the Raymond Berger Foundation for Diabetic Research in Lausanne and by National Institutes of Health Grants AM 24092 and AG 00233. We thank Ms. D. Penseyres, Ms. E.Maeder and Ms. B. Mayland for their active and skillful participation in the biochemical experiments, and Ms. M.C.Evraere, Ms. M.Donner, and Ms. J.A. Palmieri for their secretarial assistance. Dr. K.Acheson is supported by a grant from the Nestle Company, Switzerland.

\section{References}

1. DeFronzo RA, Ferrannini E, Koivisto V (1983) New concepts in the pathogenesis and treatment of non-insulin dependent diabetes melitus. Am J Med 75 [Suppl 1A]: 52-81

2. DeFronzo RA, Deibert D, Hendler R, Felig P (1979) Insulin sensitivity and insulin binding to monocytes in maturity-onset diabetics. J Clin Invest 63:939-946

3. DeFronzo RA, Simonson D, Ferrannini E (1982) Hepatic and peripheral insulin resistance: a common feature of insulin-independent and insulin-dependent diabetes. Diabetologia 23: 313-319

4. Kolterman OG, Gray RS, Griffin J, Burstein P, Insel P, Scarlett JA, Olefsky JM (1981) Receptor and postreceptor defects contribute to the insulin resistance in non-insulin-dependent diabetes mellitus. J Clin Invest 68: 957-969

5. Greenfield MS, Doberne L, Kramer F, Tobey T, Reaven G (1981) Assessment of insulin resistance with the insulin suppression test and the euglycemic clamp. Diabetes 30:387-392

6. Zierler KL, Rabinowitz D (1963) Roles of insulin and growth hormone, based on studies of forearm metabolism in man, Medicine 42: $385-402$

7. Jackson RA, Perry G, Rogers J, Advani U, Pilkington TRE (1973) Relationship between the basal glucose esncentration, glucose tolerance and forearm glucose uptake in maturity-onset diabetes. Diabetes 22: 751-761
8. Butterfield WJH, Whichelow MF (1965) Peripheral glucose metabolism in control subjects and diabetic patients during glucose, glucose-insulin and insulin sensitivity tests. Diabetologia 1: $43-53$

9. Kimmerling G, Javorski WC, Olefsky JM, Reaven GM (1976) Locating the site(s) of insulin resistance in patients with nonketotic diabetes mellitus. Diabetes 25: 673-678

10. Kalant N, Leibovici T, Rohan I, Oraki S (1979) Interrelationships of glucose and insulin uptake by muscle of normal and diabetic man. Diabetologia 16: 365-372

11. Luft R, Wajngot A, Efendic S (1981) On the pathogenesis of maturity-onset diabetes. Diabetes Care 4: 58-63

12. Felig P, Wanren J, Hendler R (1978) Influence of maturity-onset diabetes on splanchnic glucose balance after oral glucose ingestion. Diabetes 27: 121-126

13. Beck-Nielsen H, Pedersen O, Sorensen NS (1980) Effects of dietary changes on cellular insulin binding and in vivo insulin sensitivity. Metabolism 29: 482-487

14. Alford FP, Martin FLP, Pearson MJ (1971) The significance of interpretation of mildly abnormal oral glucose tolerance. Diabetologia 7: 173-180

15. DeFronzo RA, Jacot E, Jéquier E, Maeder E, Felber JP (1981) The effect of insulin on the disposal of intravenous glucase: results from indirect calorimetry and hepatic and femoral venous catheterization. Diabetes 30: 1000-1007

16. DeFronzo RA, Alverstrand A, Smith D, Hendler R, Hendler E, Wahren J (1961) Insulin resistance in uremia. J Clin Invest 67: 563-569

17. Meyer HU, Curchad B, Maeder E, Pahud P, Jéquier E, Felber JP (1980) Modifications of glucose storage and oxidation in nonobese diabetics, measured by continuous indirect calorimetry. Diabetes 29: 752-756

18. Felber JP, Meyer HU, Curchod B, Iselin HV, Rousselle J, Maeder E, Pahud P, Jéquier E (1981) Glucose storage and oxidation in different degrees of human obesity measured by continuous indirect calorimetry. Diabetologia 20:39-44

19. Ravussin E, Bogardus C, Schwartz RS, Robbins DC, Wolfe RR, Horton ES, Danforth E, Sims EAH (1983) Thermic effect of infused glucose and insulin in man. J Clin Invest 72: 893-902

20. Boden G, Ray JK, Smith RH, Owen OE (1983) Carbohydrate oxidation and storage in non-insulin dependent diabetic patients. Diabetes 32: 982-987

21. Bogardus C, Lillioja S, Howard BV, Reaven G, Mott D (1984) Relationship between insulin secretion, insulin action, and fasting plasma glucose concentration in nondiabetic and noninsulin-dependent diabetic subjects. J Clin Invest 74: 1238-1246

22. Randle PJE, Newsholme A, Garland PB (1964) Regulation of glucose uptake by muscle. 8. Effects of fatty acids, ketone bodies and pyruvate, and of alloxan diabetes and starvation, on the uptake and metabolic fate of glucose in rat heart and diaphragm muscles. Biochem J 93: 652-655

23. Randle PJ, Garland PB, Hales CN, Newsholme EA (1963) The glucose fatty-acid cycle. Its role in insulin sensitivity and the metabolic disturbances of diabetes mellitus. Lancet I: 785-789,

24. Ferrannini E, Barrett EJ, Bevilacqua S, De Fronzo RA (1983) Effect of fatty acids on glucose production and utilization in man. J Clin Invest 72: 1737-1747

25. Thiebaud D, DeFronzo RA, Jacot E, Golay A, Acheson K, Maeder E, Jéquier E, Felber JP (1982) Effect of long-chain triglyceride infusion on glucose metabolism in man. Metabolism 21: 1128-1136

26. Rennie MJ, Holloszy JO (1977) Inhibition of glucose uptake and glycogenolysis by availability of oleate in well-oxygenated perfused skeletal muscle. Biochem J 168: 161-170

28. Seyffert WA, Madison U (1967) Physiologic effects of metabolic fuels on carbohydrate metabolism. I. Acute effect of elevation of plasma free fatty acids on hepatic glucose output, peripheral glucose utilization, serum insulin and plasma glucagon levels. Diabetes 16: 765-776

28. DeFronzo RA, Tobin JD, Andres R (1979) Glucose clamp tech- 
nique: a method for quantifying insulin secretion and resistance. Am J Physiol 6: E214-E223

29. McGuire EAM, Helderman JH, Tobin JD, Andres R, Berman R (1976) Effects of arterial versus venous samples. An analysis of glucose kinetics in man. J Appl Physiol 41: 565-574

30. DeFronzo RA (1979) Glucose intolerance and aging. Evidence for tissue insensitivity to insulin. Diabetes 28: 1095-1100

31. DeFronzo RA, Gunnarson R, Björkman O, Olsson M, Wahren J (1985) Effects of insulin on peripheral and splanchnic glucose metabolism in noninsulin-dependent (type II) diabetes mellitus. J Clin Invest 76: 149 -155

32. Blackard WG, Nelson NC (1970) Portal and peripheral vein immunoreactive insulin concentrations before and after glucose infusion. Diabetes 19: 302-306

33. Reaven GM, Miller R (1968) Study of the relationship between glucose and insulin responses to an oral glucose load in man. Diabetes 17: $560-569$

34. Liu G, Coulston A, Chen YI, Reaven GH (1983) Does day long absolute hypoinsulinemia characterize the patient with noninsulin dependent diabetes mellitus? Metabolism 32: 754-756

35. Burstein S, Saphar P, Glaser P, Faitehman U, Myttenaere S, Nedey R (1977) Determination of energy metabolism from respiratory functions alone. J Appl Physiol 42: 117-119

36. Herbert B, Lau KS, Gottlieb CW, Bleicher SJ (1965) Coated charcoal immunoassay of insulin. J Clin Endocrinol Metab 25: $1375-1384$

37. Dole V, Meinertz H (1960) Microdetermination of long-chain fatty acids in plasma and tissues. J Biol Chem 235: 2595-2599

38. Heindel JJ, Cushman SW, Jeanrenaud G (1974) Cell-associated fatty acid levels and energy-requiring processes in mouse adipocytes. Am J Physiol 226: 16-24

39. Aguilar-Parada E, Eisentraut AM, Unger RH (1969) Pancreatic glucagon secretion in normal and diabetic subjects. Am $J$ Med Sci 257: 415-419

40. Hawk PB (1947) Kjeldahl method. In: Practical physiological chemistry, 12th edn. Blakiston, Toronto, pp 814-822

41. Evans DJ, Murray R, Kissebah AH (1984) Relationship between skeletal muscle insulin resistance, insulin mediated glucose disposal, and insulin binding. $\mathrm{J}$ Clin Invest 74: 1515-1525

42. DeFronzo RA, Ferrannini E, Hendler R, Felig P, Wahren J (1983) Regulation of splanchnic and peripheral glucose uptake by insulin and hyperglycemia in man. Diabetes $32: 35-45$
43. Bogardus C, Lillioja S, Stone K, Mott D (1984) Correlation between muscle glycogen synthase activity and in vivo insulin action in man. J Clin Invest 73: 1185-1190

44. Frayn $\mathrm{KN}$ (1983) Calculation of substrate oxidation rates in vivo from gaseous exchange. J Appl Physiol 55: 628-634

45. Schalch DS, Kipnis DM (1965) Abnormalities in carbohydrate tolerance associated with elevated plasma nonesterified fatty acids. J Clin Invest 44: 2010-2020

46. Nestel PJ, Carroll KF, Silverstein MS (1964) Influence of free fatty acid metabolism on glucose tolerance. Lancet II: 115-117

47. Lillioja S, Bogardus C, Mott DM, Kennedy AL, Knowler WC, Howard BV (1985) Relationship between insulin-mediataed glucose disposal and lipid metabolism in man. J Clin Invest 75 : $1106-1115$

48. Cherrington AD, Williams PE, Harris MS (1978) Relationship between the plasma glucose level and glucose uptake in the conscious dog. Metabolism 27: 787-791

49. DeFronzo RA, Simonson DC, DelPrato S (1985) Glucose resistance in diabetes. Evidence for impaired insulin-independent glucose uptake. Diabetes 34 [Suppl.1]: 87A

50. Doberne L, Greenfield MS, Schulz B, Reaven GM (1981) Enhanced glucose utilization during prolonged glucose clamp studies. Diabetes 30: 829-835

51. Jacot E, DeFronzo RA, Jéquier E, Maeder E, Felber JP (1982) The effect of hyperglycemia, hyperinsulinemia and route of glucose administration on glucose oxidation and glucose storage. Metabolism 31: 922-930

52. DeFronzo RA, Hendler R, Christensen N (1980) Stimulation of counterregulatory hormonal responses in diabetic man by a fall in glucose concentration. Diabetes 29: 125-131

Received: 1 December 1987

and in revised form: 16 May 1988

Dr. R.A. DeFronzo

Chief, Diabetes Division

Department of Medicine

University of Texas Health Science Center

7703 Floyd Curl Drive

San Antonio, Texas 78284

USA 